\title{
Cincuentenario de la última epidemia de viruela en Chile
}

\author{
ENRIQUE LAVAL R.
}

\section{Semicentennial of the last Smallpox epidemic in Chile}

Si bien se ignora dónde o cuándo apareció por primera vez la viruela, los conocimientos actuales harían pensar que uno de los poxvirus de los animales, pudo gradualmente adaptarse al hombre.

Los historiadores estiman que la viruela habría aparecido en uno de los asentamientos agrícolas del noreste de África, de China, o de la cuenca del Indo, poco tiempo después del año 10.000 a.C. Esta suposición estaría basada en las huellas de una erupción que se observan en la momia de Ramsés V y en las descripciones encontradas en textos médicos y religiosos de época no precisada, en la China y en la India.

A principios del siglo XVI, la viruela fue importada de España o África al Nuevo Mundo, a la Isla La Española en el Caribe. En 1520 se propagó de Cuba al imperio azteca de Méjico, donde al parecer, causó la muerte a más de tres millones de personas. Menos de cinco años más tarde devastó el imperio peruano. En Europa murieron de viruela, en el siglo XVIII, cinco monarcas reinantes y provocó la extinción de la Casa Real Inglesa de los Estuardo; truncó la línea de sucesión de los Habsburgo de Austria por cuatro veces en otras tantas generaciones y fue causa de una violenta pandemia después de la guerra francoprusiana en 1871. La viruela facilitó la conquista y la colonización de América por los Europeos, al diezmar las poblaciones nativas."

En Chile, dos epidemias de 1554 y 1556 merecen serias dudas respecto del diagnóstico, pero la originada en 1561, en el norte del país incuestionablemente fue de viruela y con certeza se puede señalar dicho año como punto de partida de la aparición de la enfermedad en Chile. Así Góngora de Marmolejo, al referirse cómo Francisco de Villagra sucedió al gobernador don García Hurtado de Mendoza, expresa que al arribar aquel a Coquimbo desde el Perú, el año 1561, en "desembarcando se inficiono el aire de tal manera, que dio en los indios una enfermedad de viruelas, tan malas que murieron muchos de toda suerte, que fue una pestilencia muy dañosa y por ello decían los indios de guerra, que Villagra no pudiendo sustentarse contra ellos como hechicero, había traído aquella enfermedad para matarlos, de que cierto murieron muchos de los de guerra y de paz."

Según Ferrer "dicha enfermedad se hizo endémica, presentando de tiempo en tiempo, cada cuatro años, más o menos, irrupciones que asolaron al país". ${ }^{5}$ Así se llegó al siglo XX con epidemias entre 1900 y 1923. Luego, la enfermedad dejó de ser epidémica, con casos aislados en 1931, 1935, 1944 y 1948 (estos dos últimos en la Oficina Salitrera Anita, en la pampa de Tarapacá y en la Oficina Pedro de Valdivia de Antofagasta, respectivamente). ${ }^{6}$

A fines de 1949, algunos Jefes Sanitarios Provinciales de la Zona Sur, comunicaron a la Dirección General de Sanidad, la presencia de viruela en la región fronteriza con la República Argentina. Se resolvió enviar una comisión de funcionarios técnicos para comprobar el diagnóstico. Por la circunstancia de no haber existido viruela en el país durante años, dichos técnicos carecían de la experiencia necesaria e informaron que los enfermos denunciados "presentaban varicelas graves", recomendando, sin embargo, efectuar vacunación antivariólica, debido a la baja tasa de vacunados.

La aparición de casos sospechosos en las ciudades de Santiago y Talca en marzo de 1950, permitió efectuar un estudio completo concluyéndose que presentaban un cuadro de viruela menor o benigna, llamado también alastrim. Se comprobó fehacientemente que la epidemia partía desde los primeros casos denunciados a fines de 1949, los que a su vez provenían de enfermos que habían cruzado desde Argentina por boquetes cordilleranos o se habían contagiado en viajes a ese país. Entre las cadenas epidemiológicas estudiadas se mencionó la de un indígena que vivía en la región fronteriza de la provincia de Malleco y que se dirigía a la zona argentina colindante donde estuvo en contacto, según sus propias palabras, con personas que presentaban "granos en la cara y en el cuerpo". A su regreso, enfermaron su padre de 80 años, que falleció y otras once personas de su familia. El mismo indígena, en pleno período de evolución hizo dos viajes al interior de la provincia y contagió a los individuos que tuvieron contacto directo con él, diseminando así paulatinamente la enfermedad entre la población indígena cordillerana.

Otra cadena correspondió a la iniciada "por un arriero argentino que entró al país por un paso cordillerano de la provincia de Talca, alojándose en la casa de un inquilino de una hacienda". Presentó allí los primeros síntomas. Sin embargo, continuó su viaje hasta un campamento industrial donde originó más de 150 casos.

A partir del $1^{\circ}$ de abril de 1950 , la prensa comenzó a publicar noticias sobre la epidemia de viruela, destacando "las intensas actividades desplegadas por las autoridades sanitarias con el fin de frenar el brote de viruela benigna que ha afectado a Talca y otras ciudades". 3 
La zona más comprometida por la epidemia fue la provincia de Malleco, siguiéndole las de Concepción y Talca. Las restantes presentaron tasas sensiblemente más bajas. Los casos registrados fueron 3.414 , pero se presumió que el total de enfermos fue superior, por la denuncia inicial muy incompleta, hasta alcanzar un nivel óptimo posteriormente. Además, los primeros casos correspondieron a zonas (Lonquimay y Curacautín) donde las condiciones de aislamiento y de control epidemiológico eran forzosamente muy deficientes, con propagación al resto del país a partir de esos focos.

En cuanto se confirmó la presencia de viruela por medio del diagnóstico clínico, de laboratorio y epidemiológico, la Dirección General de Sanidad adoptó todas las medidas para organizar una campaña enérgica, con la colaboración incondicional de los diferentes servicios médicos y la de otras instituciones indispensables para una campaña nacional de vacunación (Fuerzas Armadas, Carabineros, Cruz Roja, etc) La cooperación de los Servicios de Beneficencia y Asistencia Social, permitió organizar "hospitales de variolosos" en Valparaíso, Santiago. Rancagua, Curicó, Talca, Linares, Concepción, Talcahuano, Curacautín y Valdivia. No hubo casos de viruela en Tarapacá, Antofagasta ni Atacama.

La vacunación se efectuó por medio de equipos fijos y móviles; los primeros ubicados en puntos estratégicos como locales públicos (Oficinas Sanitarias, Seguro Obrero, Hospitales, Correos, Retenes de Carabineros, etc) y los segundos recorriendo fábricas, colegios, regimientos, etc y casa a casa. Los equipos estaban integrados por personal de otros servicios médicos y voluntarios previamente instruidos en la técnica de vacunación. Se utilizaron más o menos 10.000 vacunadores en toda la República y se vacunaron en los primeros diez días, 1.327.400 personas (890.000 correspondieron a Santiago). El 9 de agosto el total de vacunados ascendía a 5.328.307, cifra vecina al $90 \%$ de la población del país en esa época. ${ }^{8}$ El Presidente de la República don Gabriel González Videla fue uno de los primeros ciudadanos en ser vacunado "impulsando con su ejemplo la campaña nacional contra la enfermedad". Por otra parte, en los primeros días de abril de 1950, noticias provenientes del extranjero revelaban que "más de 200 hospitales de Escocia occidental han sido colocados en cuarentena para resguardar a los pacientes de un grave brote de viruela, en el que fallecieron cuatro personas, una de ellas médico, la doctora Janet Fleming.

La colaboración prestada por más o menos 400 estudiantes de Medicina, merece un comentario. Después de un adiestramiento rápido en la técnica de inoculación, este contingente se movilizó el primer día y sólo en Santiago vacunó a 250.000 personas en jornadas de 12 a 14 horas. $^{8}$

A partir del 10 de abril "se acordó terminar la vacunación intensiva contra la viruela benigna, continuándose la administración de vacunas en las postas permanentes".

El programa expuesto, que fue cumplido estrictamente, permitió dominar la epidemia a fines de mayo de 1950, fecha en que se observó un descenso brusco de la curva de morbilidad. La aparición de unos pocos casos en diversas regiones del país, en el resto de 1950 y a principio de 1951, reveló la persistencia de susceptibles como había sido previsto.

En Santiago la mayoría de los enfermos fueron internados en el Servicio de Medicina y Enfermedades Infecciosas del Hospital Ramón Barros Luco, "atendiéndose 78 casos con una buena evolución y sin letalidad. La duración del período de incubación, la del período pre-eruptivo y de la enfermedad total fue exactamente igual a los casos típicos de viruela mayor, siendo la única diferencia la ausencia de casos fatales".

El alto número de enfermos contagiados (125) en el medio hospitalario, refleja las dificultades que existieron en un comienzo para conseguir un aislamiento adecuado. El Hospital Regional de Concepción mostró el porcentaje más alto (68\%). En algunos casos el contagio se hizo por enfermos que ingresaron en el período de incubación o con diagnóstico errado, varicela especialmente . $^{2}$

Como se ha dicho, la benignidad del cuadro clínico y de sus complicaciones y la baja letalidad estimada en un $0,45 \%$ hicieron rubricar este proceso como viruela menor. El estudio anátomo-patológico de 10 fallecidos, efectuado en Concepción, comprobó que las víctimas de la enfermedad mostraban en general precarias condiciones físicas y correspondieron en su totalidad a lactantes o mujeres embarazadas, en quienes el pronóstico es habitualmente grave. Las autopsias permitieron apreciar diversas modalidades de la enfermedad, incluyendo formas clásicas, otro algo atípico y cuadros eminentemente tóxicos. ${ }^{2}$

Las autoridades sanitarias en declaración a la prensa el día 17 de abril de 1950, "reconocieron que no habría existido epidemia de viruela si se hubiera cumplido la ley de vacunación, sosteniendo que no se habría registrado ninguna defunción por esa causa"’3.

Finalmente, es bueno recordar que la Organización Mundial de la Salud (OMS), certificó en 1980, la erradicación total de la viruela en el mundo.

\section{Bibliografía}

1.- Informe Final de la Comisión para la Certificación de la Erradicación de la Viruela. OMS. 1980.

2.- Lyons A S, Petrucelli R J. Medicine. An. Ilustrated History. H.N. Abrahams Ed. N. York. USA. 1987.

3.- Lain Estralgo P. Historia Universal de la Medicina. Salvat Ed. Barcelona. España. 1975.

4.- Laval M E. La viruela en Chile. An Ch Hist Mcd (1967-68) 9-10: 203.

5.- Ferrer P L. Historia General de la Medicina en Chile. T. 1. Impta. Talca. Chile. 1904.

6.- Urrutia R, Lanza L C. Catástrofes en Chile. 15411992. Ed. La Noria. Santiago de Chile. 1992.

7.- Kraljevic O R. Recuerdos de un viejo infectólogo. Pfizer. Stgo de Chile. 1998.

8.- Servicio Nacional de Salubridad. La epidemia de viruela. Rev Chil Hig Mcd Prev 1951: 13: 99.

9.- Diario El Mercurio de Santiago. 1 de abril de 1950.

10.- Ibíd. 2 de abril de 1950.

11.- Ibíd. 10 de abril de 1950.

12.- Reuter B N. Epidemia de viruela de Concepción de 1950. Estudio Anátomo-patológico. Bol Suc Biol. Concep 1950; 25: 109-17.

13.- Diario El Mercurio de Santiago. 18 de abril de 1950. 